\title{
LXIII. On planetary influences on the atmosphere
}

\section{Rev. T. Drummond}

To cite this article: Rev. T. Drummond (1816) LXIII. On planetary influences on the atmosphere, Philosophical Magazine Series 1, 48:223, 321-325, DOI: 10.1080/14786441608637675

To link to this article: http://dx.doi.org/10.1080/14786441608637675

曲 Published online: 27 Jul 2009.

Submit your article to this journal $\pi$

Џll Article views: 3

Q View related articles $\sqsubset$ 


\section{[ 321$]$}

LXIII. On Planelary Influences on the Aimosphere. By the Rev.T. DRUMMOND.

To Mr. Tilloch.

$\mathrm{S}_{\text {IR, }}-\mathrm{M}_{\text {ANKIND has from a very remote period exhibited }}$ two classes of characters, - the credulous and the incredulous. It has frequently occurred that credulity has predonimated without evidence or argument to give it sanction, and that incredulity has been cherished without any attempt to investigate the truth or falsehood of the positions in question.

The credulous and the incredulous have perhaps in no instance been more tenacious in opinion than on the sulject of planetary influence. As the object of this paper is confined to the consideration of planetary influences on the atmosphere, it is not necessary for us to investigate the ground on which philosophers of preceding periods contended for the universal prevalence of starry influences.

The hypothesis I am disposed to advocate is of great antiquity; we can trace its vestiges in remote periods-its origin baffles all chronological precision.

The doctrine of planetary influence was the foundation of the Sabian system of religions worship. It engaged the attention of Babylonian and Egyptian sages; and in every civilized state of human existence, as amongst the Perses, the Hindoos, and the Chinese-people whose antiynity distances all competition-we find that astrological science wias accounted worthy the attention of the most intelligent persons. Modern philosophers have limited the tille of science to astronomy, i. e. the elementary part; and consigned astrology, i. e. the application of elementary knowledge combining observation and inferences, to disrepute, if not to oblivion.

Indiscriminate ridicule, censure, or contempt, are not worthy of admission within the pale of philosophy. - Whilst the fabulous stories of the Pleiades or the Hyades having been the daughters of Atlas, are mere modern romances, comparatively speaking, or at best enigmatical vehicles of some concealed truth, and most probably of Grecian invention, - we must look to the extensively prevalent Sabian system of theology as far more ancient, and we may rationally infer that in its primitive reception it was not chargeable with idolatry.

The etymology of the term is uneertain,-perhaps from Sabos in Arabia*, - but Sabianism or Sabism is now generally understood to imply the worship of the heavenly bodies.

* There can be little doubt, 1 think, about the etymology of this word. It is derived from sats $t$ saba, conimonly pronounced saba, an army or Vol. 48. No. 223. Nov. 1816. 
If we resolve to reject every doctrine which has at any time boen misapprehended, or whose truths have by the multitude been confounded with error, the subjects for our belief will be very limited.

The opinion adopted by the Perses, the Chinese, and the ancient Greeks, appears to have been, that a supreme ruling invisible Power exists, with whom the planets and stars are so connected as to be the creative and productive powers, the immediate agents of the Deity. Thence the Chinese of the ancient school, at this day worship Tien or Theaven, by which they understand the supreme power presiding in that vast expanse where the planets and stars have their respective motions. From the positions of the planets, from the rising and setting of the constellations, they have time immemorial attempted to predict the vicissitudes of the seasons; and since every change in the atmosphere must be the effect of some secondary operating cause, it is at least decorous to investigate before we condemn a practice which has received the testimony of ages in its defence.

The Sabian system of worship, wnich enrois the planets and stars in its ritual as jhjects of adoration, is to be considered one of the many instances in which error has tarnished the lustre of truth.

If we refer to the history of the patriarchal families, we find the primitive religion in its purity; -in the records of the Old Testament we perceive that the patriarchs retained those correct principles of true religion, which acknowledged the unity and supremacy of the Deity, and limited religious homage to that one God, whilst the planetary bodies and all secondary causes were regarded merely as the ministers of the will of God. -An extract from Josephus may serve to testify that the idea is correct with regard to Abraham :

"Abraham was the first* that adventured to preach up the doctrine of one GoD, the Almighty Maker and Creator of alt things in heaven and earth : and that for all the comforts we enjoy in this world, it is to his infinite goodness, not to any power in ourselves, that we stand indebted for them. This he argued from the orderly course of things, both at sea and land, in their times and seasons, and from his observations upon the motions and infuluences of the sun, moon, and stars; insomuch that, without an over-ruling and an administering providence to keep the whole a-going, the whole frame of the universe must drop into confusion; and consequently that all we have to trust

host. In the sacred volume the son, moon, and stars are called the saba, that is, the host, of heaven (Deut. iv. 19); and the Israelites were expressly commanded not to worship the saba, but bim who made them, and who is therefore called Jenovan תisy sabuoth-the Lord of Hosts.-EDIT.

* $i$, e. amongst the Chaldeans of that period. 
to, for matters either of pleasure, profit, or necessity, depends singly upon the good-will and bounty of the first mover; so that it is to him alone that we are to render all honour and thanksgiving, without assuming any thing to ourselves."-L'Estrange's Josephus, chap. viii.

The Book of Job is a fair specimen of Sabian theology before the less refined sentiments of what is now denominated Sabian worship were introduced. -The beautiful poem, with the argumentative narratives contained in the Book of Job, is of great antiquity; - no internal evidence assists us in determining the age in which it was written, nor the author to whom we are indebted for a composition which has merited, and will ever merit, the admiration of mankind. The personification of the agent of evil is a specimen of poetical licence, but the subsequent matter is simple in its theology and correct in its ethics. The sublimity of thought and the pure morality contained in this work are admitted to be superior to the productions of Homer.

Although many allusions are made to the customs of patriarchal ages, or rather of the early stages of civilization, it may not be without hesitation inferred that the Book of Job was fabricated beyond the precincts of improved civilization and highly cultivated talent.-The arguments of the friends of Job are founded on principles similar to those which have in several periods of the world formed the bases of academic questions.

I have no wish, sir, to fill your pages with theological or ethical discussions, nor to involve your readers with investigations concerning the probable writer of that excellent composition,-whether Enoch, or any of his predecessors or cotemporaries, is of no moment, - the state of astronomical, and, if the distinction must be observed, of astrological science, at the æra in which the poem was written, is deducible from the mention of Mazaroth, Arcturus, Orion, and the Pleiades, more especially from the mention made of the sweet influences of the Pleiades; whence we must infer that the writer was no stranger to the prevalent opinion of sidereal influence.

What the writer of the Book of Job appears to have credited, - what Abraham from the statements in Josephus appears to have corroborated,--may, I heg leave to presume, be considered as having constituted a part of that knowledge which Moses acquired amongst the Egyptians, and in which Daniel and his associates became proficients in the court of Babylon.

Impelled by a desire of attaining the knowledge of truth, and with that view desirous of divesting myself of all prejudice, I must avow that I see nothing in a creed considering the starry host as the agents of Deity by their mutual attractions and repulsions, at the same time limiting to the Divine Being all the reverence $\mathrm{X} 2$ 
of worship which Jewish prophets may not be supposed to have adopted, and to which Christian divines may not be allowed to subscribe. Regarding those astrological atmospherical observations which have escaped the ravages of time, as the fragments of a science which was successfully cultivated in many ancient periods, I presume that the attention of the moderns directed to the changes in the atmosphere, and to the coincident situation of the planets, may improve our meteorological knowledge, and enable us to recover all that was ever known by the sages of antiquity.

The sun is generally allowed to be the exciter of what we call heat in the atmosphere and on our earth; and it is not requisite on this occasion to inquire whether the sun emits light and heat, or whether it excites them in the body of the air and the surface of the earth.

The moon is commonly supposed to have no atmosphere like our own; but that it has an influence on whatever constitutes our atmosphere is generally acknowlenged.

The. infuences of the sun and moon are so well authenticated by the observances on the periodical flow and ebb of the tides in the waters encompassing our earth, that no differences in opinion exist relative to the ordinary causes and effects ; and it may not be unworthy our attention to inquire, whether extraordinary ebbings and fowings are not imputable to other planetary and sidereal influences.

No one questions that what is usually expressed by the term attraction operates between bodies of different magnitudes; and confining our attention to what is, denominated the solar system, whatever properties or qualities are ordained by the divine Creator to regulate the movements and limit the approximation of the planetary bodies, must be conceived to operate in every part of the space in which they revolve.

It is of no moment in the present consideration how far the late Rev. J. Wesley was correct in his remark, that astronomers assuming the magnitudes of the heavenly bodies infer their distances, and assuming their distances infer their magnitudes: the question is, what plansible reason can be assigned whence we mayinfer that their relative situations produce those atmospherical changes, "the skiey influences" to which we are subjected.

A small ball freely suspended near the side of a mountain is by an undiscernible influence moved from a perpendicular direction,--a small magnet has a property of producing an effect not only at a distance through the intervening portion of air, but of manifesting its operation, although glass, wood, and a variety of other substances, intervene; - -yet it is by many regarded as incredible that such large bodies as Jupiter and Saturn can 
have any corresponding action or effect. The planetary bodies, according to modern philosophers, are too remote to act on each other, or on the atmosphere around us. The varying belts of Jupiter and the extended ring of Saturn may be atmospheres, yet not perfectly similar to the aërial envelope surrounding our earth; but every planet must be surrounded with a fluid, whatever its peculiar gaseous quality; and in and through that fluid the planet, whether by mechanical or chemical attraction or repulsion, must be conceived to rarefy, condense, or otherwise operate. As the moon is capable of transmitting its influence through the surrounding medium to the waters and to the earth which compose our globe, we may infer that each planet has a certain sphere of operation: and however we may suppose the energy of that operation to decrease as the distances increase, or whatever may be the intervening medium, we must allow planetary is as capable as lunar influence, of exerting its proportion of agency through that medium.

$$
\text { Yours respectfully, }
$$

Priory, Gray Friars, Norwich,

T. Drummond.

Nov. 7, 1816.

LXIV. Some Oliservations on the Salt Mines of Cardona, made during a Tour in Spain, in the Summer of 1814. By Thomas Stewart Traill, M.D. Member of the Geological Society ${ }^{*}$.

Tress Thest the ima celebrated mines occupy the head of a small valley in the immediate vicinity of Cardona, a town in the province of Catalonia.

This valley extends about half a mile in length, from the river Cardonero to the mines, in a direction from east-south-east to west-north-west. Its north western side is bounded by a very steep and lofty ridge, the summit of which is crowned by the town and castle of Cardona. The opposite boundary is somewhat less elevated; but both sides are considerably higher than the upper surface of the fossil salt. On entering this valley, the attention is arrested by bold eliffs of a greyish-white colour, which are soon discovered to consist of one vast mass of ealt. The sides and bottom of the valley are composed of reddish-brown clay, forming a thick bed, from which here and there large imbedded masses of rock salt project in the manner of more ordinary rocks; especially along the winding ascent which leads up to the town of Cardona. The summits of the ridges which bound

* From the Transactions of the Geological Society, vol. iii. 